\title{
Turbulent flows interacting with varying density canopies
}

\author{
Laurence Pietri $^{1, a}$, Alexandre PetrofF ${ }^{2}$, Muriel Amielh $^{1}$ and Fabien Anselmet ${ }^{1,3}$ \\ 1 Institut de Recherches sur les Phénomènes Hors Equilibre (IRPHE), Aix-Marseille Université, C.N.R.S., Technopôle \\ de Château-Gombert, 49 rue F. Joliot-Curie, B.P. 146, 13384 Marseille Cedex 13, France \\ 2 Air Quality Research Division, Environment Canada,4905 Dufferin St. Toronto, M3H 5T4, Canada \\ 3 École Centrale Marseille, Technopôle de Château-Gombert, 38 rue F. Joliot-Curie, 13451 Marseille Cedex 20, France
}

Received 20 April 2009

\begin{abstract}
In the case of dense and homogeneous canopies, it is well-known that canopy flows are similar to mixing layer flows (so-called mixing layer analogy). When the canopy becomes sparser, a transition between the mixing layer and the boundary layer perturbed by interactions between element wakes occurs. This transition has still to be fully understood and characterized. An experimental work has been developed in order to study this transition for various density canopies.
\end{abstract}

Key words: Turbulence / canopy flow / canopy density / spatial heterogenity

Résumé - Écoulements turbulents en interaction avec des couverts de différentes densités. Il est maintenant bien connu que les écoulements au travers de couverts végétaux denses et homogènes ont des propriétés semblables à celles des écoulements de couche de mélange. C'est ce qu'on appelle l'analogie de couche de mélange. Quand le couvert devient moins dense, une transition se produit : on passe d'un écoulement de couche de mélange à celui d'une couche limite plus ou moins perturbée par l'interaction entre les sillages des éléments du couvert. Un travail expérimental a été développé afin de comprendre et caractériser cette transition dans des couverts de densité variable.

Mots clés : Turbulence / écoulement de couvert / densité du couvert / hétérogénéité spatiale

\section{Introduction}

In the current context of environmental preservation and air quality control, it is important to understand and characterize canopy flows such as those developing over urban areas $[1-3]$ or natural vegetation $[4,5]$. Vegetation canopies and urban canopies can be differentiated by considering the ratio of the shear length scale and the canopy height [6]. Urban canopies are qualified as shallow (ratio 1) whereas vegetative canopies are deep (ratio $<<1$ ). While flows through canopies have been extensively studied [5], there are a few works related to flows through sparser canopies. It is very well-known now that canopy flow behavior follows the mixing layer analogy when canopies are relatively dense $[4,7]$. This feature has been proved for rigid canopies as well as for flexible ones [8]. But the mixing-layer analogy is only acceptable for relatively dense and homogeneous canopies [5]. When the vegetation density decreases, the canopy flow

\footnotetext{
${ }^{a}$ Corresponding author: pietri@irphe.univ-mrs.fr
}

characteristics evolve from the mixing layer towards a standard boundary layer which is more or less perturbed by isolated canopy elements. A quick overview of literature data underlines the point that turbulent flows through low density canopies have not been studied thoroughly yet. Therefore, the objective of the present study is to identify parameters which govern the transition from the mixing layer flow to the boundary layer flow perturbed by wake interaction in canopies of low density.

\section{Experimental facility}

The experimental work is developed in a wooden-made open wind tunnel (15 m long). The working section is $5 \mathrm{~m}$ long with a rectangular section $\left(0.46 \times 0.56 \mathrm{~m}^{2}\right)$. The floor slope is adjustable to maintain a zero pressure gradient boundary layer in every configuration (boundary layer or canopy flow). Holes, $0.025 \mathrm{~m}$ regularly spaced, were drilled in the last $2 \mathrm{~m}$ section of the floor to receive canopy elements. The canopy covers an area of $2 \times 0.56 \mathrm{~m}^{2}$ and 


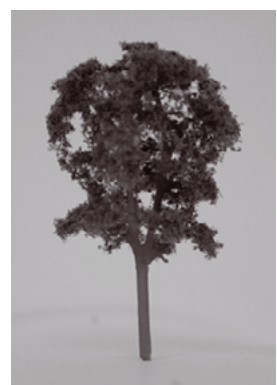

(a) Round tree

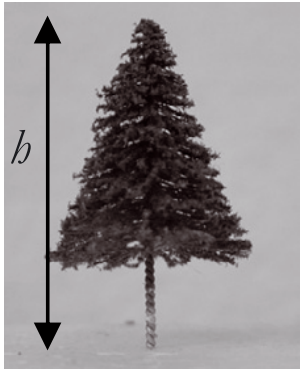

(b) Coniferous tree

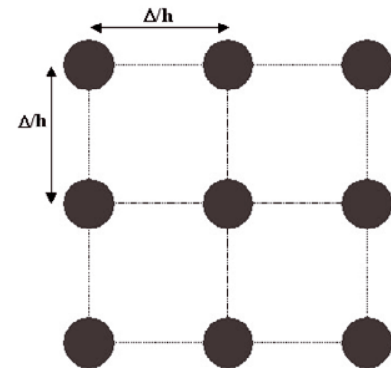

(c) Alignment

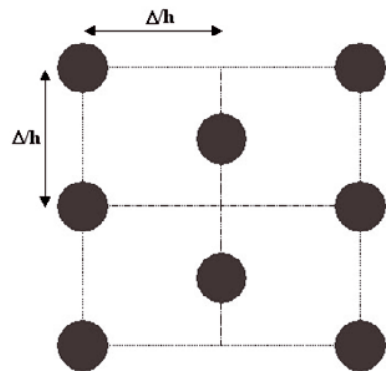

(d) Staggered arrangement

Fig. 1. Canopy element (a,b) and spatial ground arrangement (c,d).

Table 1. Roughness density $(\lambda)$, friction velocity $\left(u^{*}\right)$, ratio of $u^{*}$ and the mean velocity taken at $z=h\left(U_{h}\right)$ for each canopy configuration.

\begin{tabular}{|c|c|c|c|c|c|c|c|}
\hline & \multirow{2}{*}{$\Delta / h$} & \multicolumn{2}{|c|}{$\lambda$} & \multicolumn{2}{|c|}{$u^{*}\left(\mathrm{~m} \cdot \mathrm{s}^{-1}\right)$} & \multicolumn{2}{|c|}{$u^{*} / U_{h}$} \\
\hline & & (2) & $\mathbf{A}$ & 줄 & $\mathbf{A}$ & . & $\mathbf{A}$ \\
\hline \multirow[t]{3}{*}{ alignment case } & 1 & 0.48 & 0.22 & 1.14 & 0.9 & 0.26 & 0.12 \\
\hline & 1.5 & 0.2 & 0.09 & 0.89 & 0.8 & 0.1 & 0.09 \\
\hline & 2 & 0.13 & 0.06 & 0.74 & 0.65 & 0.07 & 0.05 \\
\hline \multirow[t]{2}{*}{ staggered case } & 1 & 0.46 & 0.21 & & $1.05 / 1.26$ & & $0.16 / 0.19$ \\
\hline & 2 & 0.12 & 0.06 & 1.08 & 0.9 & 0.19 & 0.11 \\
\hline
\end{tabular}

the ratio of the tree height $\mathrm{h}$ to the section height is $1: 9$. Velocity measurements are performed by laser Doppler velocimetry (LDV, one-component and two-component systems) and particle image velocimetry (PIV). These techniques are well-suited for exploring flows through canopies, particularly in the region of the interaction between tree wakes where turbulence intensities can attain values significantly greater than $30 \%$. In order to minimize laser reflection, walls of the working section have been painted black. Seeding is provided by four perfume diffusers feeding a perforated grid placed at the wide angle diffuser inlet of the wind tunnel before the settling chamber. It is performed with olive oil droplets whose mean diameter has been checked by phase Doppler anemometry to be around $1 \mu \mathrm{m}$. For LDV measurements, statistical moments are calculated from at least 10000 samples. Convergence of statistical moment calculations is then largely confirmed to within $1 \%$ for the two first moments and $6 \%$ for cross-moments. For PIV measurements, 3400 images are acquired and 1700 fields are computed. Statistical moments up to the second order, including crossmoments of $\mathrm{u}$ and $\mathrm{w}$ velocity components, are calculated. 1000 processed fields are needed to warrant the convergence of the two velocity first moments within $2 \%$ while 1400 processed fields are needed for cross-moment convergence within $5 \%$.

The canopy is made of a variable number of artificial coniferous or round trees (Figs. 1a-1b). The tree mean height $h$ is $0.05 \mathrm{~m}$. Stems and trunks are metal. Stems are flocked with a fine green foam representing needles or leaves. Trees can be disposed on the wind tunnel floor following two different schemes: an alignement or a staggered scheme (Figs. 1c-1d). The roughness density $\lambda$ of the canopy is based on the conical form of coniferous trees and it is estimated from image analysis for round trees. $\lambda$ depends on the type of tree, on the element spacing and on the ground arrangement (Tab. 1). Three spacings $\Delta$ have been chosen: $0.05 \mathrm{~m}, 0.075 \mathrm{~m}$ and $0.1 \mathrm{~m}$ or, in terms of tree height: $h, 1.5 h$ and $2 h$. In the staggered case, only two spacings are possible: $h$ and $2 h$.

Although spatial averaging is recommended for analysing global turbulence characteristics of canopy flows, local data are generally presented in this paper in order to highlight the variability of the turbulence properties within the canopy and to analyse in detail the similarities and differences between the staggered configuration and the alignment.

\section{Influence of the canopy density and spatial ground arrangement}

\subsection{Mean longitudinal velocity profiles}

Figure 2 displays the vertical evolution of the mean longitudinal velocity for conifer canopies (Fig. 2a) and round tree canopies (Fig. 2b) for different element spacings and for both ground arrangements. Profiles obtained from PIV measurements (Fig. 2b) are spatially averaged along the longitudinal direction. In the lowest part of the canopy, a mean velocity secondary maximum occurs for all considered cases but it is relatively weak for the sparsest aligned canopies. This secondary maximum is 


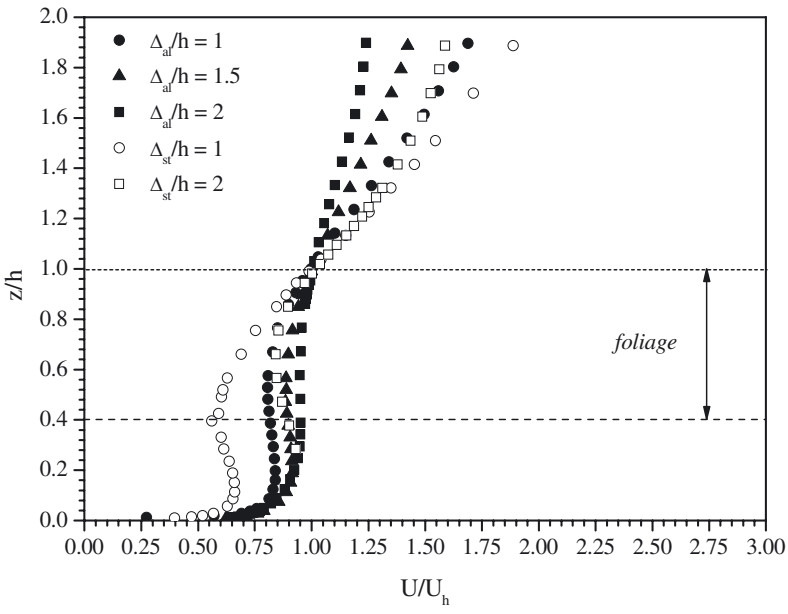

(a)

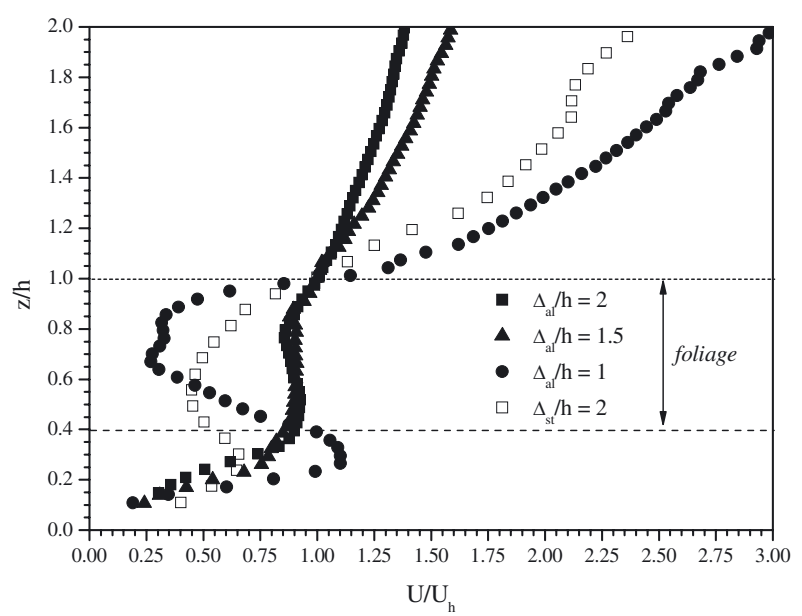

(b)

Fig. 2. Vertical profiles of the mean longitudinal velocity for all canopy densities and both configurations (a) Coniferous tree canopies (LDV measurements). (b) Round tree canopies (PIV measurements).

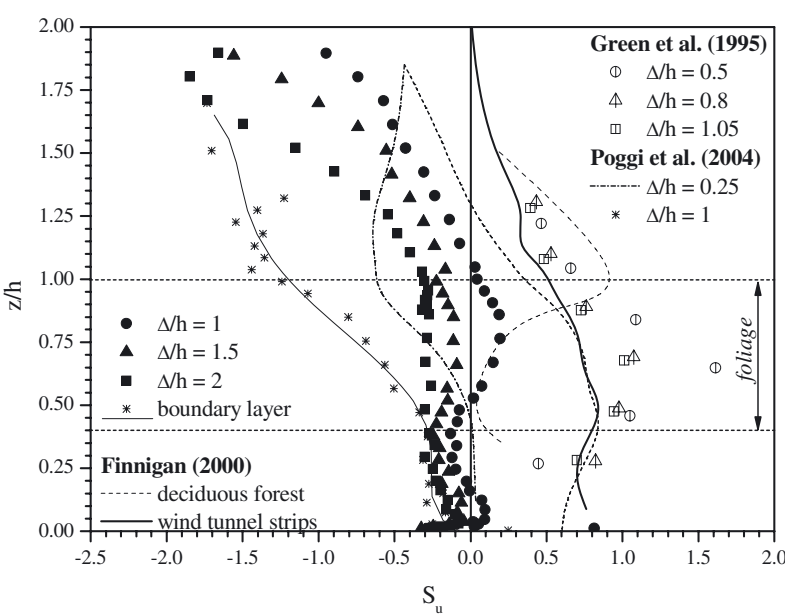

(a)

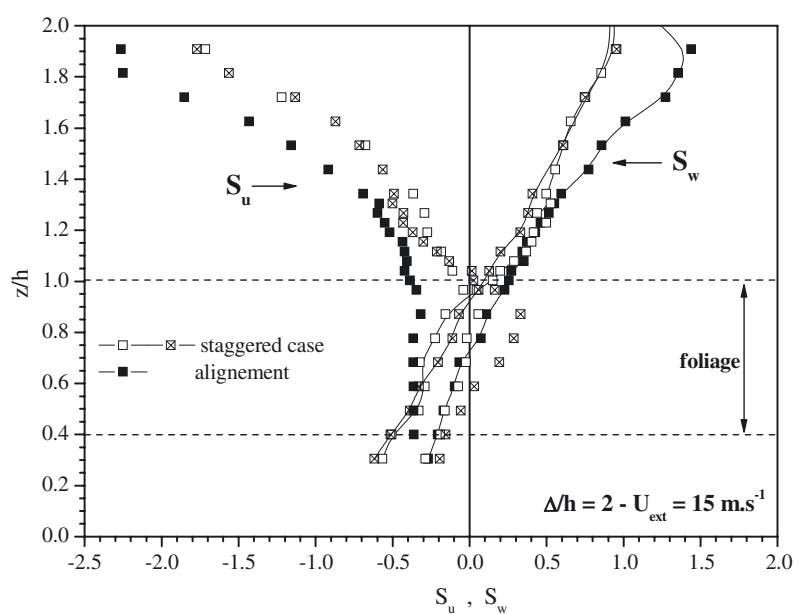

(b)

Fig. 3. Vertical profiles of velocity skewness, conifer canopies (a) longitudinal velocity; aligned arrangement (b) velocity longitudinal and vertical components; both spatial arrangements.

sometimes mentioned [9-11] and is due here to the empty space under the foliage.

Near the top, the profile gets more and more inflectional as the canopy density increases. The existence of an inflection point at the canopy top, $z=h$, in the mean longitudinal velocity profile is a first clue for the mixing layer analogy. For the aligned canopy, the inflectional region tends to disappear when the canopy becomes sparser, resulting in an increase of the shear length scale associated to the velocity field. Velocity profiles are more inflectional in staggered canopies. The ground arrangement of the roughness elements seems to play a more dominant role with regard to the mean velocity field than the canopy roughness density, the latter not varying from one configuration to the other for the same spacing (see Tab. 1).

\subsection{Skewness profiles}

The third moment of velocity fluctuations is an interesting characteristic of canopy flows. The skewness $S_{u}=$ $\overline{u^{3}} /{\overline{u^{2}}}^{3 / 2}$ highlights the presence of large extreme fluctuations and the departure from a symmetric Gaussian-like distribution of fluctuations. When $\Delta / h$ decreases, the skewness of the velocity longitudinal component $S_{u}$ inside the aligned canopy evolves from being negative towards being slightly positive (Fig. 3a). The largest positive values remain however smaller than the positive values observed in real canopy flows $[5,11]$. The influence of canopy density is more marked than for previous studies $[11,12]$ since the skewness sign changes with spacing. Green's skewness values remain strongly positive, even for the 
Table 2. Shear length scales $\left(L_{s} / h\right)$ calculated at $z=h$ for each canopy configuration.

\begin{tabular}{|c|c|c|c|c|c|c|c|}
\hline & \multirow{2}{*}{$\Delta / h$} & \multicolumn{2}{|c|}{$L_{s} / h$} & \multicolumn{2}{|c|}{ [11] } & \multicolumn{2}{|c|}{ [13] } \\
\hline & & 䣓 & A & $\lambda$ & $L_{s} / h$ & $\lambda$ & $L_{s} / h$ \\
\hline \multirow[t]{3}{*}{ alignment case } & 1 & 0.34 & 1.4 & 1 & 0.45 & 1.4 & 0.44 \\
\hline & 1.5 & & 2.2 & 0.5 & 0.66 & 0.54 & 0.66 \\
\hline & 2 & 1.6 & 3.9 & 0.25 & 0.7 & 0.24 & 0.87 \\
\hline \multirow[t]{2}{*}{ staggered case } & 1 & & 0.9 & & & & \\
\hline & 2 & 0.3 & 1.9 & & & & \\
\hline
\end{tabular}

sparsest canopy, while Poggi's tend only towards zero except in the half upper region of the canopy where the values decrease to -0.5 . Under every spacing configuration, the skewness recovers, outside the canopy, negative values that are typical of a boundary layer, in agreement with other canopy measurements in wind tunnel (except Finnigan's data [5]) and hydraulic channel [12]. For natural canopies $[5,11]$, it is likely that measurements have not been performed far enough above the vegetation top to allow the flow to recover its external characteristics.

The ground geometrical arrangement of the canopy appears to play an important role although the canopy density is the same considering a same spacing. For $\Delta / h=2$ for instance (Fig. 3b), the skewness is negative inside the aligned canopy while it is strictly positive under the staggered configuration inside the foliage region. The skewness value increases with canopy density, reaching value as high as 0.75 inside the staggered canopy (not shown here). The canopy turbulence is thus strongly influenced by the ground arrangement.

The skewness of the velocity vertical component $S_{w}=$ $\overline{w^{3}} /{\overline{w^{2}}}^{3 / 2}$ takes negative values inside the canopy foliage (Fig. 3b). $S_{u}$ and $S_{w}$ evolve with opposite signs in agreement with literature review [5] indicating an incursion of the fluid from the external layer.

\subsection{Shear length scales}

The shear length scale $L_{s}$ is deduced from the mean longitudinal velocity profile at the vertical position $z=h$ :

$$
\frac{L_{s}}{h}=\frac{1}{h} \frac{U_{h}}{\left(\frac{\partial U}{\partial z}\right)_{h}}
$$

This scale controls turbulence length scales in canopy flows and corresponds to the half vorticity scale in mixing layers [4]. It is a measure of the shear strength: stronger the shear, smaller the shear length scale.

$L_{s} / h$ decreases when canopies become denser and takes its smallest values for the staggered canopy case (Tab. 2). Moreover, when the canopy density is high as for round tree canopies, the shear is stronger.

The shear length scale for the $\Delta / h=1$ alignment arrangement is relatively similar to that obtained for the $\Delta / h=2$ staggered arrangement for both types of canopy. The staggered configuration seems to break more easily large structures than the alignment configuration although the tree spacing of the former configuration is twice the latter. This remark underlines the main influence of the geometrical arrangement of the canopy.

Table 2 provides also some results obtained by Green et al. [11] in natural orchards and Novak et al. [13] in staggered artificial canopies (artificial Christmas tree branches). The scales we calculate from our data are slightly larger than theirs. This is mainly due to larger canopy densities in our experiment.

\section{Conclusion}

The canopies studied in this paper are characterized by low densities and then can be qualified as sparse canopies. This project aims to fill a gap in our understanding of the canopy turbulence since sparse canopies have been a little studied until now. A new experimental set-up was designed to study the transition from a boundary layer and its driving parameters. We observed and quantified the role of the canopy density, its ground arrangement and the obstacle shape on this transition through the evolution of different turbulent flow characteristics such as the mean wind velocity, the different skewness factors and the shear length.

It seems that the ground arrangement of the canopy plays an important role on the turbulence development of a canopy flow. When its density increases, characteristics for a staggered canopy evolve towards those of a mixing layer more than for an aligned canopy. For a same canopy density, the ground arrangement of the canopy would have to affect the canopy drag coefficient. A more significant parameter to analyse would be then the product $c_{d} a h$ where $c_{d}$ is the drag coefficient and $a$ the leaf area density as introduced by Nepf et al. [14]. Indeed, if $c_{d} a h<0.04$, the flow could be considered as a boundary layer without inflexion point whereas the inflexion point would be very pronounced if $c_{d} a h>0.1$.

\section{References}

[1] C.S.B. Grimmond, T.R. Oke, Aerodynamic properties of urban areas derived from analysis of surface form, J. Appl. Meteorol. 38 (1999) 1262-1292

[2] R.W. Macdonald, Modelling the mean velocity profile in the urban canopy layer. Boundary-Layer Meteorol. 97 (2000) 25-45 
[3] R.E. Britter, S.R. Hanna, Flow and dispersion in urban areas. Ann. Rev. Fluid. Mech. 35 (2003) 469-496

[4] M.R. Raupach, J.J. Finnigan, Y. Brunet, Coherent eddies in vegetation canopies: the mixing layer analogy, Boundary-Layer Meteorol. 78 (1996) 351-382

[5] J.J. Finnigan, Turbulence in plant canopies. Ann. Rev. Fluid. Mech. 32 (2000) 519-571

[6] S.E. Belcher, N. Jerram, J.C.R. Hunt, Adjustment of a turbulent boundary layer to a canopy of roughness elements. J. Fluid. Mech. 488 (2003) 369-398

[7] Y. Brunet, J.J. Finnigan, M.R. Raupach, A wind tunnel study of air flow in waving wheat: single-point velocity statistics. Boundary-Layer Meteorol. 70 (1994) 95-132

[8] M. Ghisalberti, H. Nepf, The structure of the shear layer in flows over rigid and flexible canopies. Envir. Fluid. Mech. 6 (2006) 277-301

[9] R.N. Meroney, Characteristics of wind and turbulence in and above model forests. J. Appl. Meteor. 7 (1968) 780-788
[10] B.D. Amiro, Comparison of turbulence statistics within three boreal forest canopies, Boundary-Layer Meteorol. 51 (1990) 99-121

[11] S.R. Green, J. Grace, N.J. Hutchings, Observations of turbulent air flow in three stands of widely spaced Sitka spruce, Agric For Meteorol. 74 (1995) 205-225

[12] D. Poggi, A. Porporato, L. Ridolfi, J.D. Albertson, G.G. Katul, The effect of vegetation density on canopy sublayer turbulence, Boundary-Layer Meteorol. 111 (2004) $565-587$

[13] M.D. Novak, J.S. Warland, A.L. Orchansky, R. Ketler, S. Green, Wind tunnel and field measurements of turbulent flow in forests, Part I: uniformly thinned stands. Boundary-Layer Meteorol. 95 (2000) 457-495

[14] H. Nepf, M. Ghisalberti, B. White, E. Murphy, Retention time and dispersion associated with submerged aquatic canopies, Water Resour Res 43 (2007) W0422, doi: 10.1029/2006WR005362 